\title{
Tinnitus Among Medical Students Using Personal Sound System
}

\author{
Syam Sasidharan, ${ }^{1}$ Sheetal Rai, ${ }^{1}$ Gangadhara Somayaji ${ }^{1}$
}

\section{Introduction}

$\underline{\text { ABSTRACT }}$

Statistical data on prevalence of tinnitus in India and on the relationship between exposure to recreational sound/music and the presence of tinnitus are scarce. This study was conducted to assess relationship between tinnitus and the use of personal sound system(PSS) in medical students.

\section{Materials and Methods}

A questionnaire based study was conducted on 100 randomly selected medical students to assess their sound habits with the use of PSS. Information on commonly used intensity, frequency, duration of use, type of earphones and severity of tinnitus was sought. Conventional frequency audiometry $(0.25-8 \mathrm{kHz})$ was also performed.

Results

The prevalence of tinnitus was found to be $33 \%$, which was on the higher side of the global prevalence data. All the medical students surveyed in this study used personal sound system. Majority of the students (45\%) used PSS less than 1 hour daily. More than $60 \%$ of the students complaining of tinnitus preferred louder settings in their PSS.

\section{Discussion}

The most common personal sound system used was mobile phones. No statistically significant association was seen with relation to the type of personal sound system, the type of ear phone used, average duration of use and hearing loss. Tinnitus was found to have statistically significant association with volume in our study with majority having tinnitus listening to higher levels of sound.

Conclusion

Use of personal sound system is common in medical students. Though duration of use of the personal sound system was not associated with the complaint of tinnitus, exposure to louder sounds had statistically significant association with tinnitus.

Keywords

Tinnitus; Students, Medical; Cell Phones; Leisure Activities; Noise.

$\mathrm{T}$ innitus is defined as a sound perceived for more than $5 \mathrm{~min}$ at a time, in the absence of any external acoustic stimulation of the ear and not occurring immediately after exposure to loud sound. ${ }^{1}$ Common causes for it are ear diseases (conductive and sensorineural hearing loss), neurologic disease, bone/ joint disorder, endocrine/metabolic diseases, mental disorders, ototoxic drugs, temporomandibular joint disorder or unknown. ${ }^{1}$

Tinnitus is classified into two types, objective and subjective. Objective tinnitus is the sounds or noises that can be heard by others as well as the sufferer with or without the need of a stethoscope or other forms of noise amplifying instrumentation. ${ }^{2}$ It can be because of a vascular phenomenon or due to the spasm of the muscle of the middle ear or the palate. In patients with tinnitus it is present in less than $1 \%$. Whereas in subjective tinnitus, the neural signals responsible for tinnitus, may be produced by a lesion in the cortex itself or in the auditory pathway. ${ }^{2}$

Worldwide prevalence statistics indicate that $10 \%$ to $33 \%$ of the population has tinnitus. ${ }^{3,4}$ Although there is positive relationship with age, according to some studies $75 \%$ of adolescents had experienced at least a single episode of tinnitus. ${ }^{5}$

The popularization of Personal Sound System (PSS)

1 - Department of ENT, Yenepoya Medical College,

Mangalore, Karnataka

\section{Corresponding author:}

Dr Syam Sasidharan

email: dr.syamsasidharan@gmail.com 
because of its low price, increased storage capacity, easy downloads and reduced size of the devices has increased over time, especially among the younger population. A survey of 18-25 year olds in Nottingham (UK) revealed that, listening to various devices made up $58 \%$ of the total average leisure-time activity. ${ }^{6}$ Similarly studies have shown that $94.3 \%$ of Korean adolescents used personal music players ${ }^{7}$ and $66.7 \%$ of college students used iPods in USA. ${ }^{8}$

Given that tinnitus can be due to temporary or permanent noise-induced hearing loss, and it can act as a warning sign even before the hearing loss becomes apparent, we sought to study the relationship between exposure to recreational sound and the presence of tinnitus. It will also form a baseline data for further research in understanding tinnitus in the younger people.

\section{Materials and Methods}

The study was conducted on medical students of an urban Medical College in Karnataka. Ethical clearance was obtained for this study. A sample size of 100 was selected and subjects were selected by random sampling. Students with pre existing ear disease, previous ear surgery, those with active upper respiratory infections and nasal allergy, pregnant and breast feeding women, those with systemic illness, those with noise trauma and those on medications (antibiotics, diuretics, antimalarials, cytotoxic drugs and analgesics) were excluded.

Students who were selected for the study was asked to fill a questionnaire which included demographic data, containing open and closed questions - addressing their sound habits with the use of PSS, information on commonly used intensity, frequency and duration of use, type of earphones, and symptoms associated with exposure, highlighting the presence of tinnitus. A detailed ENT evaluation was followed by Pure Tone Audiometry conducted in a sound treated room using a calibrated clinical audiometer.

Statistical analysis was done using Chi square test and Pearson correlation.

\section{Results}

All the 100 subjects were found to be using personal sound system and prevalence of tinnitus was found to be 33 percent. The most common personal sound system used was mobile phones (45\%). (Table I, $p$ value $=0.4)$ No statistically significant association was found with the type of personal sound system. The most common tool used for hearing was earphones. $38 \%$ used earphones alone, while $24 \%$ used earphones along with speakers and $18 \%$ used earphones and headphones. (Table II, $\mathrm{p}$ value $=0.455$ ) There was no statistically significant association between tinnitus and tool used for hearing. In earphones, $45 \%$ used insertion type of earphones, $40 \%$ used both insertion and earmuffs, $13 \%$ used ear muffs alone. There was no statistically significant association between tinnitus and the type of ear phone used. (Table III, p value $=0.364$ ) $45 \%$ of the students surveyed used PSS for less than 1 hour, $29 \%$ used it between one to three hours, $18 \%$ between three to five hours \& $8 \%$ for more than 5 hours. (Table IV, $\mathrm{p}$ value $=0.576$ ) There was no association between tinnitus and daily use time. $50 \%$ students surveyed showed the usage of PSS to be more than 5 years. (Table V, $p$ value $=0.414$ ) There was no statistically significant association between tinnitus and total use of PSS in years.

The daily use time was one to three hours in majority $(35 \%)$ of subjects using personal sound system for more than 5 years. (Fig. 1) There is statistical association between tinnitus and volume of usage. Though majority was using low volume of one to three $(77 \%)$, the majority of tinnitus positive patients $(61 \%)$ were using a high volume in their PSS. (Table VI, p value $=0.00$ ) and Fig.2) There was no statistically significant association between the use of PSS and hearing loss. (Table VII, $\mathrm{p}$ value $=0.240)$ It was found that $11 \%$ had bilateral conductive hearing loss, $2 \%$ unilateral conductive hearing loss and $2 \%$ had unilateral sensorineural hearing loss.

\section{Discussion}

The prevalence of subjective tinnitus in our study was found to be $33 \%$. In a similar study done on students of 
Table I : Tinnitus and type of personal sound system

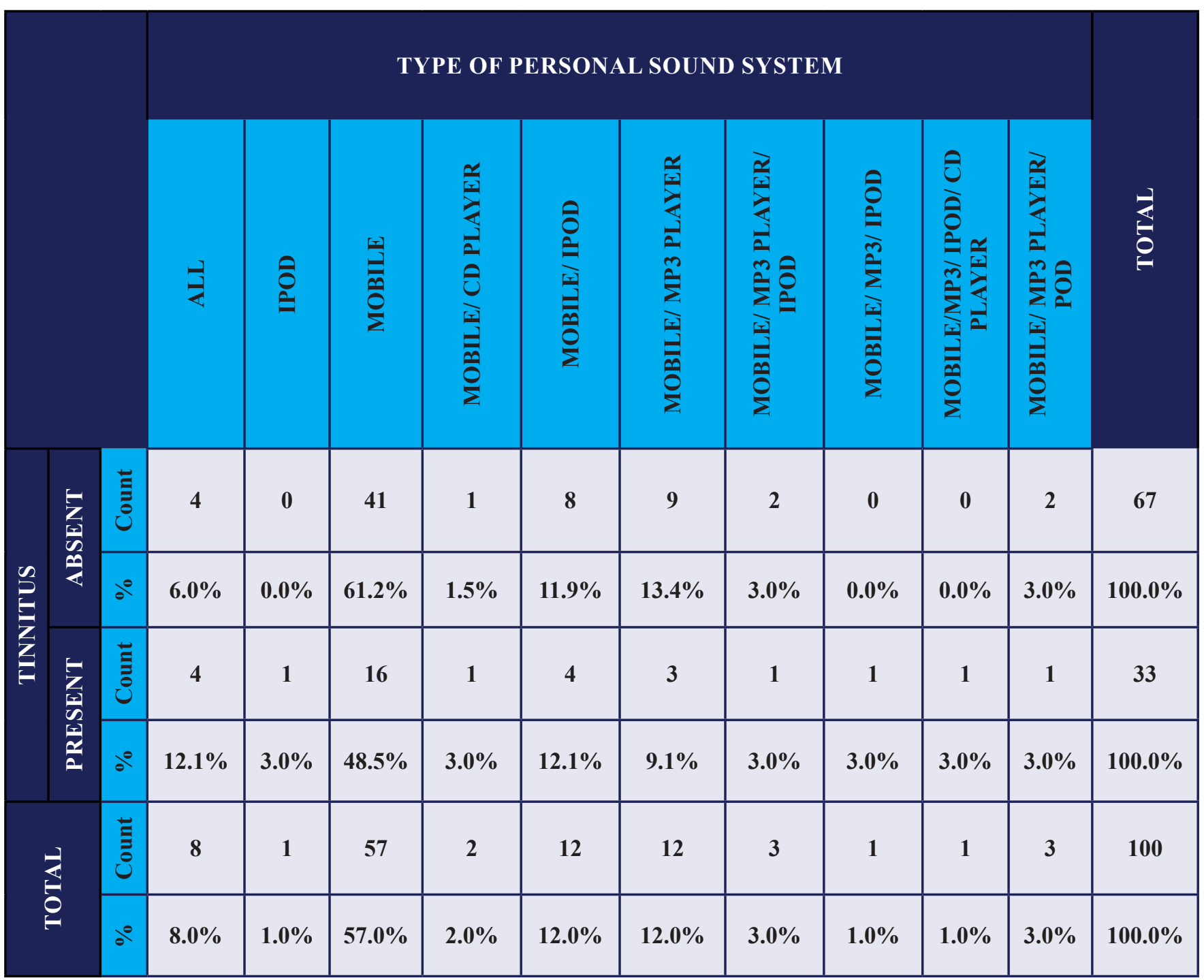

Medicine, University of Lagos, Nigeria, the prevalence was found to be $22 \% .^{9}$ This finding lies within the limits of global prevalence of tinnitus among adults which is between $10 \& 33 \%{ }^{3,4}$ However no such statistical data is available for Indian population.

The prevalence of use of PSS was found to be 100 percent in our study. A study conducted in Korea, found that $94.3 \%$ of adolescents were using personal music player.7 In USA, $66.7 \%$ of college students used iPods. ${ }^{8}$

Our study showed that the most common type of earphone used was insert type (Table III); as also found in $\mathrm{UK}^{6}$ and Korea; ${ }^{7}$ it could be because of their better appearance and lesser price. Researchers have found the insert type of earphones are more hazardous compared to headset type. ${ }^{10,11}$ This is attributed to the greater coupling of sound directly to ear in this type of earphone.

There was no statistically significant association between tinnitus and duration of exposure. Majority used PSS less than 1 hour daily (45\%), though 50\% have been using it for more than 5 years. The reduced 
Table II : Tinnitus and Tool used for hearing

\begin{tabular}{|c|c|c|c|c|c|c|c|c|}
\hline & & \multicolumn{6}{|c|}{ TOOL USED FOR HEARING } & \multirow{2}{*}{ TOTAL } \\
\hline & & ALL & EARPHONES & $\begin{array}{c}\text { EARPHONES } \\
\& \\
\text { HEADPHONES }\end{array}$ & $\begin{array}{l}\text { EARPHONES } \\
\text { \& SPEAKER }\end{array}$ & $\begin{array}{l}\text { NOT } \\
\text { USING } \\
\text { ANY }\end{array}$ & SPEAKER & \\
\hline \multirow{4}{*}{$\begin{array}{l}\stackrel{\infty}{\rho} \\
\underline{\underline{E}} \\
\underline{\underline{Z}} \\
\underline{E}\end{array}$} & छ̇ & 10 & 25 & 10 & 19 & 2 & 1 & 67 \\
\hline & $\partial^{\circ}$ & $14.9 \%$ & $37.3 \%$ & $14.9 \%$ & $28.4 \%$ & $3.0 \%$ & $1.5 \%$ & $100.0 \%$ \\
\hline & छ̇ & 7 & 13 & 8 & 5 & $\mathbf{0}$ & $\mathbf{0}$ & 33 \\
\hline & $\theta^{\circ}$ & $21.2 \%$ & $39.4 \%$ & $24.2 \%$ & $15.2 \%$ & $0.0 \%$ & $0.0 \%$ & $100.0 \%$ \\
\hline \multirow{2}{*}{$\frac{\beta}{6}$} & E & 17 & 38 & 18 & 24 & 2 & 1 & 100 \\
\hline & $\partial^{\ominus}$ & $17.0 \%$ & $38.0 \%$ & $18.0 \%$ & $24.0 \%$ & $2.0 \%$ & $1.0 \%$ & $100.0 \%$ \\
\hline
\end{tabular}

daily usage of PSS could be the reason for the lack of significant association. Researchers in Australia also found no significant association between years of use or exposure and tinnitus. ${ }^{12}$

Table III : Tinnitus and type of earphone used

\begin{tabular}{|c|c|c|c|c|c|c|c|}
\hline & \multicolumn{4}{|c|}{ TYPE OF EARPHONE USED } & \multirow{2}{*}{ TOTAL } \\
\hline & & & Вотн & EAR MUFFS & INSERTION & NIL & \\
\hline \multirow{4}{*}{ 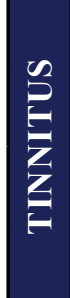 } & \multirow{2}{*}{ ABSENT } & Count & 25 & 7 & 33 & 2 & 67 \\
\hline & & $\%$ & $37.3 \%$ & $10.4 \%$ & $49.3 \%$ & $3.0 \%$ & $100.0 \%$ \\
\hline & \multirow{2}{*}{ PRESENT } & Count & 15 & 6 & 12 & $\mathbf{0}$ & 33 \\
\hline & & $\%$ & $45.5 \%$ & $18.2 \%$ & $36.4 \%$ & $0.0 \%$ & $100.0 \%$ \\
\hline & \multirow{2}{*}{ TOTAL } & Count & 40 & 13 & 45 & 2 & 100 \\
\hline & & $\%$ & $40.0 \%$ & $13.0 \%$ & $45.0 \%$ & $2.0 \%$ & $100.0 \%$ \\
\hline
\end{tabular}


Table IV : Daily use time of PSS (in hours)

\begin{tabular}{|c|c|c|c|c|c|c|}
\hline & & \multicolumn{4}{|c|}{ DAILY USE TIME ( IN HOURS) } & \multirow{2}{*}{ TOTAL } \\
\hline & & $\begin{array}{l}\text { MORE } \\
\text { THAN } 5\end{array}$ & $\begin{array}{l}\text { ONE TO } \\
\text { THREE }\end{array}$ & $\begin{array}{c}\text { THREE TO } \\
\text { FIVE }\end{array}$ & $\begin{array}{l}\text { ZERO TO } \\
\text { ONE }\end{array}$ & \\
\hline ABSENT & Count (\%) & $5(7.5 \%)$ & $19(28.4 \%)$ & $10(14.9 \%)$ & $33(49.3 \%)$ & 67 \\
\hline PRESENT & Count (\%) & $3(9.1 \%)$ & $10(30.3 \%)$ & $8(24.2 \%)$ & $12(36.4 \%)$ & 33 \\
\hline TOTAL & Count $(\%)$ & $8(8 \%)$ & $29(29 \%)$ & $18(18 \%)$ & $45(45 \%)$ & 100 \\
\hline
\end{tabular}

Table V : Tinnitus and duration of use of PSS (in years)

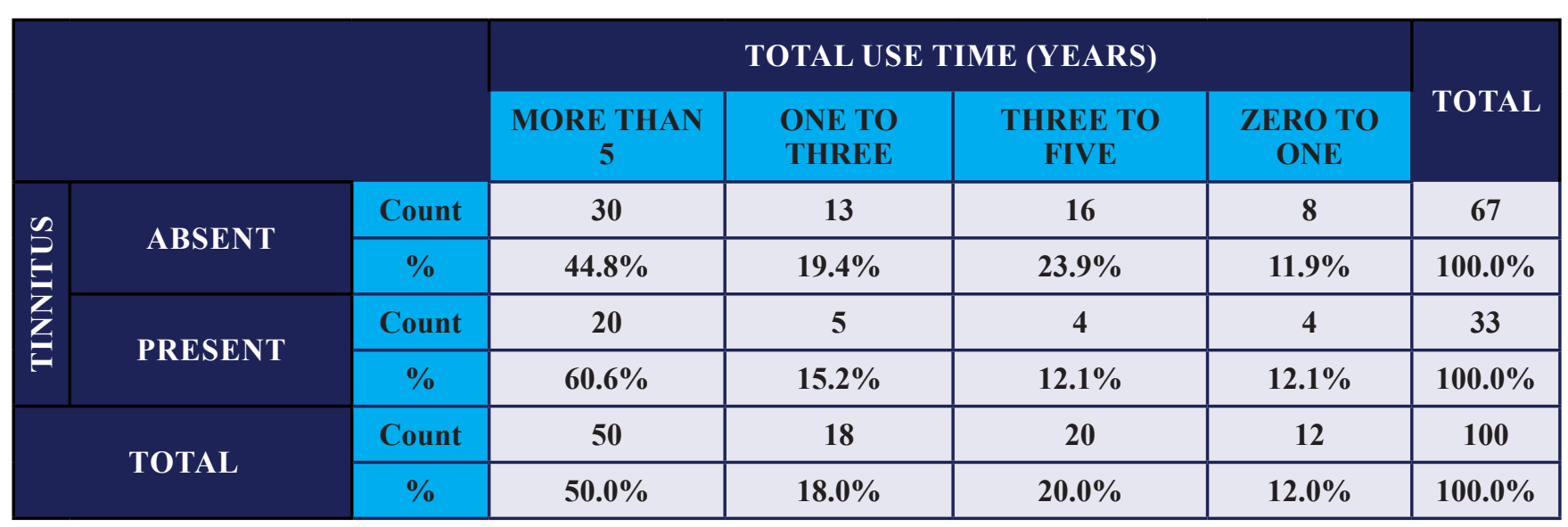

Table VI : Tinnitus and preferred loudness of the sound system

\begin{tabular}{|c|c|c|c|c|c|c|}
\hline & & & \multicolumn{4}{|c|}{ LOUDNESS } \\
\hline & & & $\begin{array}{l}\text { EIGHT TO } \\
\text { TEN }(80 \% \\
\text { to maximum } \\
\text { volume) }\end{array}$ & $\begin{array}{l}\text { FOUR TO } \\
\text { SEVEN } \\
\text { (upto } 70 \% \\
\text { of maximum } \\
\text { volume) }\end{array}$ & 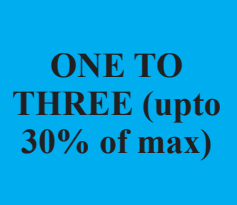 & TOTAL \\
\hline \multirow{2}{*}{$\begin{array}{l}\mathscr{D} \\
\underline{\underline{E}} \\
\underline{\underline{Z}} \\
\underline{Z}\end{array}$} & ABSENT & Count (\%) & $1(1.5 \%)$ & $0(0 \%)$ & $66(98.5 \%)$ & 67 \\
\hline & PRESENT & Count (\%) & $20(60.6 \%)$ & $2(6.1 \%)$ & $11(33 \%)$ & 33 \\
\hline \multicolumn{2}{|c|}{ TOTAL } & Count (\%) & $21(21 \%)$ & $2(2 \%)$ & 77 (77\%) & 100 \\
\hline
\end{tabular}




\title{
Daily use time (hours) for tinnitus positive subjects using PSS for $>5$ years
}

\author{
$\square$ zero to one $\square$ one to three $\square$ three to five $\square>$ five
}

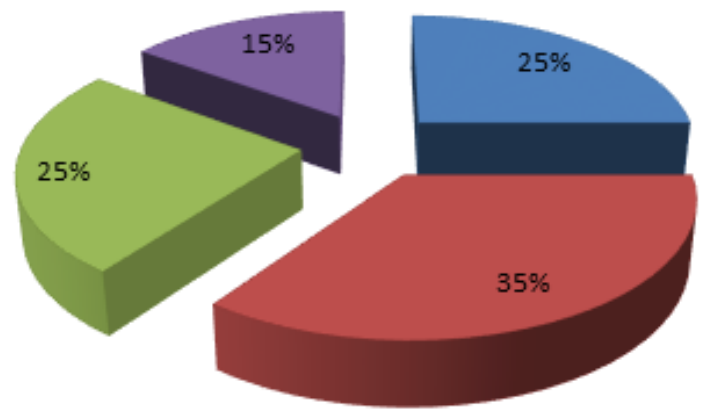

Fig.1. Daily use time (hours) in tinnitus positive patients using PSS $>5$ years

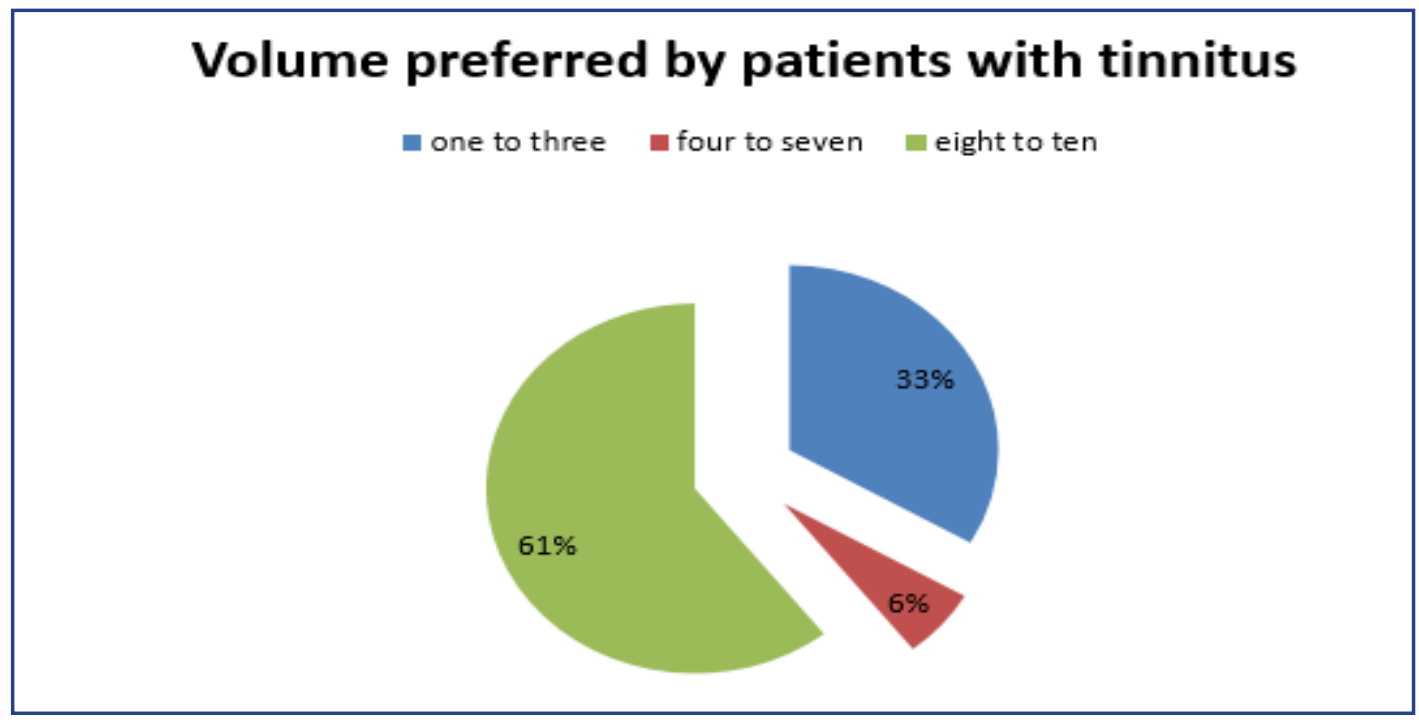

Fig.2. Preferred volume of the sound system in tinnitus positive patients

Tinnitus was found to have statistically significant association with volume in our study with majority having tinnitus listening to higher levels of sound. This association was not established in other similar studies as in the study done on students of Medicine, University of Lagos, Nigeria. ${ }^{9}$

When the severity of tinnitus was asked to be classified as appreciable only in silent environment, continuously present but not affecting the day to day activities or continuously present affecting the day to day activities, all of them felt it as appreciable only in silent environment.

Additionally it was also found that $2 \%$ had sensorineural hearing loss, $2 \%$ unilateral moderate conductive hearing loss and $11 \%$ had bilateral moderate conductive hearing loss. Though there was no statistically significant association, it is estimated that noise induced hearing loss can occur in about $10-30 \%$ of 
Table VII : Tinnitus and Hearing

\begin{tabular}{|c|c|c|c|c|c|c|c|}
\hline & & & \multicolumn{4}{|c|}{ HEARING } & \multirow[b]{2}{*}{ TOTAL } \\
\hline & & & Normal & $\begin{array}{c}\text { Bilateral } \\
\text { Moderate } \\
\text { Conductive } \\
\text { hearing loss }\end{array}$ & $\begin{array}{l}\text { Sensorineural } \\
\text { hearing loss }\end{array}$ & $\begin{array}{l}\text { Unilateral } \\
\text { moderate } \\
\text { conductive } \\
\text { hearing loss }\end{array}$ & \\
\hline \multirow{2}{*}{$\begin{array}{l}\stackrel{D}{\rho} \\
\underline{\underline{E}} \\
\underline{Z}\end{array}$} & ABSENT & Count (\%) & $59(88.1 \%)$ & $5(7.5 \%)$ & $1(1.5 \%)$ & $2(3.0 \%)$ & 67 \\
\hline & PRESENT & Count (\%) & $\begin{array}{c}26 \\
78.8 \%)\end{array}$ & $6(18.2 \%)$ & $1(3.0 \%)$ & $0(0 \%)$ & 33 \\
\hline \multicolumn{2}{|c|}{ TOTAL } & Count $(\%)$ & $85(85 \%)$ & $11(11 \%)$ & $2(2.0 \%)$ & $2(2 \%)$ & 100 \\
\hline
\end{tabular}

PSS users after 5 or more years of use, which is due to exposure to the high-intensity noise over a long period of time. ${ }^{13}$

\section{Conclusion}

The prevalence of subjective tinnitus in our study is within the limits of global prevalence of tinnitus. No statistically significant associations were found between the presence of subjective tinnitus with the type of ear phone used or duration of use but statistically significant association was seen with the loudness of sound. Further studies in the younger population are, therefore, recommended to fully assess tinnitus.

\section{References}

1. Michael G. Scott-Brown's Otorhinolaryngology, Head and Neck surgery. 7th edition, Volume 3. Great Britain: Hodder Arnold; 2008. 3594-19

2. Makar SK, Biswas A, Shatapathy P. The Impact of Tinnitus on Sufferers in Indian Population. Indian J Otolaryngol Head Neck Surg. 2014; 66 (Suppl 1): S37-S51

3. Davis A, Refaie AE. Epidemiology of tinnitus. In: Tyler R, Editor.Tinnitus handbook. San Diego: Singular Publishing Group; 2000.1-23

4. Lasisi AO, Abiona T, Gureje O. Tinnitus in the elderly : profile, correlates and impact in the Nigerian study of ageing. Otolaryngol Head Neck Surg. 2010; 143(4): 510-5
5. Gilles A, Van Hal G, De Ridder D, Wouters K, Van de Heyning P.Epidemiology of noise - induced tinnitus and the attitudes and beliefs towards noise and hearing protection in adolescents. PLOS One. 2013 ; 8(7): e70297

6. Smith PA, Davis A, Ferguson M, Lutman ME. The prevalence and type of social noise exposure in young adults in England. Noise \& Health. 2000; 2(6): 41-56

7. Kim MG, Hong SM, Shim HJ, Kim YD, Cha CI, Yeo SG. Hearing threshold of Korean adolescents associated with the use of personal music players. Yonsei Med J. 2009 ; 50(6): 771-6

8. Torre P 3rd. Young adults' use and output level settings of personal music systems. Ear Hear. 2008 ; 29 (5):791-9

9. Sunny D, Nkiruka C, Abayomi O.Subjective tinnitus and its association with use of ear phones among students of the College of Medicine, University of Lagos, Nigeria. International Tinnitus Journal 2012; 17(2): 169-72

10. LePage EL, Murray NM. Latent cochlear damage in personal stereo users : a study based on click - evoked otoacoustic emissions. Med J Aust. 1998 ; 169(11-12): 588-92

11. Meyer-Bisch C. Epidemiological evaluation of hearing damage related to strongly amplified music (personal cassette players, discotheques, rock concerts)--high-definition audiometric survey on 1364 subjects. Audiology. 1996 ; 35(3): 121-42

12. Williams W. Noise exposure levels from personal stereo use. Int J Audiol. 2005; 44(4): 231-6

13. Vogel I, Verschuure H, van der Ploeg CP, Brug J, Raat H. Estimating adolescent risk for hearing loss based on data from a large school based survey. Am J Public Health. 2010 ;100(6):1095-100. 